\title{
Assessment of the Role of Maternal Angiogenic Factors and Nitric Oxide in Prediction of Preeclampsia
}

\author{
Olfat Shaker*, Fatma Taha*, Salwa Fayez*, \\ Mohmmed Shehata**, Dalia Ahmed*** \\ Departments of Medical Biochemistry *, Obstetrics \& Gynecology ** \\ and Public Health \& Community Medicine ***, \\ Faculty of Medicine, Cairo University
}

\begin{abstract}
Preeclampsia has been proposed to be an antiangiogenic state that may be detected by the determination of the concentrations of the soluble vascular endothelial growth factor receptor- 1 (sVEGFR-1) and placental growth factor (PIGF) in maternal blood even before the clinical development of the disease. Aim: The aim of the present study was to determine the role of the combined use of uterine artery Doppler velocimetry (UADV) and maternal plasma PIGF , sVEGFR-1 and NO products concentrations for the prediction of preeclampsia in high-risk women.and to compare these parameters between patients with mild and severe preeclampsia. Subjects and Methods: A prospective cohort study was conducted on 142 women, only 112 were enrolled in the study, patients with preeclampsia were subclassified as either severe or mild preeclampsia. Blood samples were obtained between 22 and 26 weeks of gestation. Doppler ultrasound of the uterine arteries at the time of blood sampling was done. The presence of an early diastolic notch in the uterine arteries was determined. An abnormal UADV was defined as the presence of bilateral uterine artery notches and/or a mean pulsatility index above $95^{\text {th }}$ percentile for the gestational age. Maternal serum PIGF and sVEGFR-1 concentrations were determined with the use of sensitive and specific immunoassays. Nitric Oxide Colorimetric Assay was used also to measure NO products in the maternal blood. Results: Among patients with abnormal UADV, maternal plasma sVEGFR1, PIGF and NO products concentrations contributed significantly in the identification of patients destined to develop mild preeclampsia and severe preeclampsia sVEGFR1 $(\geq 2005 \mathrm{pg} / \mathrm{ml})$ and NO products $(\leq 50.90 \mathrm{umol} / \mathrm{L})$ were found to be the best predictors for preeclampsia with high sensitivity and specificity followed by PLGF ( $\leq 286.32 \mathrm{pg} / \mathrm{ml})$. In severe preeclampsia sVEGFR1 $(\geq 2900 \mathrm{pg} / \mathrm{ml})$ was the best followed by NO products $(\leq 54 \mathrm{umol} / \mathrm{L})$ and $P L G F(\leq 234.56 \mathrm{pg} / \mathrm{ml})$. Conclusion: The results of current study suggested that the identification of high concentrations of SVEGFR1 combined with low concentrations of PlGF and NO products, could be used to predict the development of preeclampsia. Key Words: Preeclampsia, soluble vascular endothelial growth factor receptor- 1 (sVEGFR1), placental growth factor (PIGF), Nitric oxide (NO).
\end{abstract}




\section{INTRODUCTION}

Pre-eclampsia, a pregnancyspecific syndrome characterized by new onset hypertension and proteinuria, is a considerable obstetric problem and a significant source of maternal and neonatal morbidity and mortality $^{(\mathbf{1})}$. It has recently been recognized that women who endure preeclampsia are at a greater risk for cardiovascular disease than nonpreeclamptic women ${ }^{(2)}$. Although the pathophysiology of preeclampsia remains undefined, placental ischemia/hypoxia is widely regarded as a key factor ${ }^{(3)}$. Inadequate trophoblast invasion leading to incomplete remodeling of the uterine spiral arteries is considered to be a primary cause of placental ischemia ${ }^{(4)}$, the poorly perfused and hypoxic placenta is thought to synthesize and release increased amounts of vasoactive factors such as soluble fms-like tyrosine kinase-1 (sFlt-1), cytokines, and possibly the angiotensin II (ANG II) type 1 receptor autoantibodies $\left(\mathrm{AT}_{1}\right.$ -

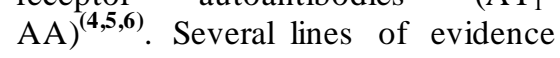
support the hypothesis that the ischemic placenta contributes to endothelial cell dysfunction in the maternal vasculature by inducing an alteration in the balance of circulating levels of angiogenic/antiangiogenic factors such as vascular endothelial growth factor (VEGF), placental growth factor (PlGF), and sFlt$1^{(\mathbf{7 , 8 , 9 , 1 0})}$. Recent data suggest that circulating sFlt-1 concentrations may predict the clinical onset of preeclamptic symptoms $^{(\mathbf{9 , 1 1}, \mathbf{1 2})}$. VEGF is primarily recognized for its potent angiogenic and mitogenic effects on endothelial cells, VEGF exerts its actions mainly by two receptors, VEGF receptor-1 and -2, also known as Flt-1 and the kinase domain region (Flk/KDR), respectively ${ }^{(13)}$. A soluble and endogenously secreted form of Flt-1 is produced mainly in the placenta by alternative splicing and contains the extracellular ligandbinding domain but not the transmembrane and cytoplasmic portions $^{(\mathbf{1 4})}$. Soluble fms-like tyrosine kinase 1 (sFlt1) (also known as soluble vascular endothelial growth factor [VEGF] receptor 1 [s VEGFR1]), a circulating antiangiogenic protein that sequesters the proangiogenic proteins placental growth factor (PlGF) and VEGF, is increased before the onset of clinical disease in the circulation of women with preeclampsia ${ }^{(5)}$. sFlt-1 disrupts VEGF signaling either by binding VEGF and PlGF or by forming heterodimers with the Flk/ KDR receptor $^{(\mathbf{1 6})}$. Although sFlt-1 is not a vasoconstrictor, it does significantly inhibit the dilatory actions of both VEGF and PlGF in vitro, and chronic elevations in circulating concentrations result in increased blood pressure ${ }^{(5,17)}$. Considerable clinical evidence has accumulated that preeclampsia is strongly linked to an imbalance between proangiogenic (VEGF and PlGF) and antiangiogenic (sFlt-1) factors in the maternal circulation $^{(\mathbf{9}, 10,5,18)}$. Recently, studies have reported that increased sFlt-1 may have a predictive value in diagnosing preeclampsia since concentrations seem to increase before manifestation of overt symptoms (e.g., 
hypertension and proteinuria) ${ }^{(\mathbf{9 , 1 5})}$. Substantial evidence indicates that nitric oxide (NO) production is elevated in normal pregnancy and that these increases appear to play an important role in the renal vasodilatation of pregnancy ${ }^{(\mathbf{1 9})}$.

Studies from several laboratories indicate that chronic NO synthase inhibition in pregnant rats produces hypertension associated with peripheral and renal vasoconstriction, proteinuria, intrauterine growth restriction, and increased fetal morbidity ${ }^{(\mathbf{2 0 , 2 1 )}}$. Currently there is no widely accepted screening test for the prediction of preeclampsia in individual women. The development of an accurate biomarker for preeclampsia in high-risk women has the potential to substantially improve care by allowing closer prenatal monitoring, recognition of preeclampsia earlier in the disease course, expeditious administration of steroids for fetal lung maturity, and appropriate antihypertensive therapy.

Recently, it has been reported that UADV between 22 and 25 weeks of gestation is the "best test" for the identification of patients destined to develop preeclampsia, compared with biochemical indicators in the maternal plasma. Abnormal uterine artery Doppler velocimetry $(\mathrm{UADV})^{(\mathbf{2 2})}$, as well as abnormal maternal plasma concentration of proangiogenic and antiangiogenic factors are risk factors for the subsequent development of preeclampsia $^{(23)}$.

\section{Aim of the work}

The aim of the present study was to determine the utility of maternal plasma concentration of the angiogenic factor PlGF and the antiangiogenic factor sVEGFR-1 for the prediction of preeclampsia in the mid trimester of pregnancy in combination with uterine artery Doppler velocimetry (UADV).

\section{SUBJECTS \& METHODS}

A prospective cohort study was conducted between January 2007 and April 2009, patients were recruited from those attending the gynecology Clinic at Kasr El Aini Hospital, Cairo University.

Inclusion criteria were pregnancy less than 24 weeks' gestation at enrollment and at least 1 of the following risk factors for preeclampsia: pregestational diabetes mellitus, chronic hypertension, chronic kidney disease, maternal age 18 years or younger, obesity, systemic lupus erythematosus, or prior history of preeclampsia. Patients with chronic hypertension, multiple pregnancies, fetal anomalies, or chronic renal disease were excluded from the study.

All women provided wrote informed consent before the collection of plasma samples.

Plasma samples were obtained at the time of ultrasound examination between 22 and 26 weeks of gestation. Preeclampsia was diagnosed according to published guidelines (24), the presence of gestational hypertension (systolic blood pressure $\geq 140 \mathrm{mmHg}$ or diastolic blood pressure $\geq 90 \mathrm{mmHg}$ on at least 2 occasions, 6 hours to 1 week apart) and proteinuria ( $\geq 300 \mathrm{mg}$ in a 24 -hour urine collection or 1 dipstick measurement of $\geq 2+$ ).

Patients with preeclampsia were subclassified as either severe or mild 
preeclampsia. Severe preeclampsia was defined as severe gestational hypertension (diastolic blood pressure $\geq 110 \mathrm{~mm} \mathrm{Hg}$ ) and mild proteinuria or mild gestational hypertension and severe proteinuria (a 24- hour urine samples that containe $₫ 3.5 \mathrm{~g}$ protein or a urine specimen of $3+$ proteins by dipstick measurement).

Doppler ultrasound of the uterine arteries at the time of blood sampling was done. The presence of an early diastolic notch in the uterine arteries was determined according to the criteria proposed by Bower et al (25). An abnormal UADV was defined as the presence of bilateral uterine artery notches and/or a mean pulsatility index of $95^{\text {th }}$ percentile for the gestational age. The mean pulsatility index was calculated by measuring the pulsatility index of the right and left uterine arteries.

\section{Sample collection}

Venipuncture was performed, and the blood was collected into tubes. Samples were immediately cooled to $4{ }^{\circ} \mathrm{C}$ and centrifuged at 3,000 rpm for 10 minutes. Serum was stored at $80^{\circ} \mathrm{C}$ until assay.

\section{Human PIGF and SVEGFR-1 assays:}

The concentrations of s VEGFR-1 were measured with an enzyme-linked immunosorbent assay (R\&D Systems, Minneapolis, $\mathrm{MN})^{\mathbf{( 2 6 )}}$.

A specific and sensitive enzymelinked immunosorbent assay was used to determine concentrations of PlGF in maternal plasma (R\&D Systems) $)^{(\mathbf{1 5})}$.

\section{Nitrite Assay:}

Serum nitrates\& nitrites (Nitric Oxide Colorimetric Assay Kit, BioVision, Mountain View, CA) ${ }^{(27)}$.

\section{Statistical analysis:}

The data was coded and entered using the statistical package SPSS version 12. The data was summarized using descriptive statistics: mean, standard deviation, minimal and maximum values for quantitative variables and number and percentage for qualitative values. Statistical differences between groups were tested using Chi Square test for qualitative variables, ANOVA (analysis of variance) for quantitative normally distributed variables and Nonparametric Mann Whitney test and Kruskal Wallis test for not normally distributed quantitative variables. Correlations were done to test for linear relations between quantitative variables. Logistic regression analysis was done to test for significant predictors for preeclampsia. Receiver operator characteristic (ROC) curves were constructed to evaluate the predictive potential of each biomarker for preeclampsia occurrence and severity. P-values less than or equal to 0.05 were considered statistically significant.

\section{RESULTS}

Of 142 patients meeting inclusion criteria, only 112 were enrolled in the study. Of these, 13 were excluded due to lack of pregnancy outcome data. For this analysis, we also excluded 14 subjects with multiple gestations, given large differences in sFlt1 and PlGF for singleton vs. multiple gestations $^{(28)}$. And 3 subjects who developed gestational hypertension without proteinuria. Analyses therefore included 112 women, of 
these, 57 did not develop preeclampsia, 17 developed mild preeclampsia and 38 developed severe preeclampsia.

Baseline characteristics and pregnancy outcomes are shown in (Table 1). Subjects with mild and severe preeclampsia had a higher body mass index $(P 1, P 2<0.001)$ and a higher incidence of chronic hypertension $(P 1, \quad P 2<0.001)$ as compared with those who did not develop preeclampsia (normotensive group). Also, the blood pressure was significantly higher in severe group than the mild one (p3<0.001).

As expected, patients with severe preeclampsia were delivered at an earlier gestational age, had a higher mean arterial pressure, and delivered smaller infants than subjects in the control and mild groups.

A significant difference in all other pregnancy outcome parameters as (Birth weight, placental weight, Gestational age at delivery and mean pulsatile index) was found between the studied groups.

Table (2) shows significant increase in mean s VEGFR1 levels in subjects who developed mild and severe preeclampsia, as compared with those who did not develop preeclampsia (P1, P2 <0.001), while no significant difference was found between the mild and severe groups (P3 >0.05).

In the severe group, the mean serum PlGF levels were significantly lower as compared with those without preeclampsia and mild group (P2, P3 $<0.001)$.
The mean levels of serum NO products were significantly decreased in both mild and severe groups as compared with normotensive one (P1, P2 $<0.001$ ), but no significant difference was found between the mild and severe groups ( $\mathrm{P} 3>0.05$ ).

When examining all patients with preeclampsia, a significant correlation was observed between sVEGFR1, PLGF and NO products and pregnancy outcome characteristics as shown in table (5).

An abnormal UADV was present in $49.1 \%(55 / 112)$ of the study population.

Two $(1.9 \%)$ of the all studied groups showed IUF death, all were diagnosed as severe cases and represent $(5.3 \%)$ of the studied severe group, while 24 of severe preeclamptic subjects (63.2\%) and only one of mild cases ( $5.9 \%$ ) showed IUGR and six subjects (15.8\%) were SGA.

Receiver operating characteristic curve (ROC Curve) was performed to examine the diagnostic performance of maternal plasma PlGF, sVEGFR1 and NO products concentrations in the identification of the patients destined to develop mild and/or severe preeclampsia.

sVEGFR1 $(\mathrm{pg} / \mathrm{ml})$ and $\mathrm{NO}$ products (umol/L) were found to be the best for preeclampsia with high sensitivity and specificity followed by PLGF $(\mathrm{pg} / \mathrm{ml})$.While in severe preeclampsia, sVEGFR1 (pg/ml) was the best followed by NO products (umol/L) and PLGF (pg/ml). (Tables 3, 4 and Figures 1, 2). 
Table (1): Characteristics and pregnancy outcomes of study subjects

\begin{tabular}{|c|c|c|c|c|c|c|}
\hline Characteristic & $\begin{array}{l}\text { Normotensive } \\
\text { subjects } \\
(n=57)\end{array}$ & $\begin{array}{l}\text { Mild } \\
\text { preeclampsia } \\
(n=17)\end{array}$ & $\begin{array}{l}\text { Severe } \\
\text { preeclampsia } \\
(n=38)\end{array}$ & $P 1$ & $P 2$ & P3 \\
\hline Maternal age & $27.77 \pm 9.60$ & $29.41 \pm 7.31$ & $27.26 \pm 8.35$ & $>0.05 \mathrm{NS}$ & $>0.05 \mathrm{NS}$ & $>0.05 \mathrm{NS}$ \\
\hline Parity & $1.77 \pm .88$ & 1.76 & $1.73 \pm .89$ & $>0.05 \mathrm{NS}$ & $>0.05 \mathrm{NS}$ & $>0.05 \mathrm{NS}$ \\
\hline$B M I\left(\mathrm{~kg} / \mathrm{m}^{2}\right)$ & $25.36 \pm 4.83$ & $31.00 \pm 3.64$ & $29.15 \pm 4.32$ & $<0.001^{*}$ & $<0.001^{*}$ & $>0.05 \mathrm{NS}$ \\
\hline$S B P(\mathrm{~mm} / \mathrm{Hg})$ & $103.68 \pm 12.62$ & $142.64 \pm 5.62$ & $169.73 \pm 15.68$ & $<0.001^{*}$ & $<0.001^{*}$ & $<0.001^{*}$ \\
\hline $\mathrm{DBP}(\mathrm{mm} / \mathrm{Hg})$ & $65.87 \pm 8.61$ & $94.41 \pm 4.28$ & $108.84 \pm 13.25$ & $<0.001^{*}$ & $<0.001^{*}$ & $<0.001^{*}$ \\
\hline Birth weight/kg & $3.54 \pm .24$ & $3.08 \pm .29$ & $2.20 \pm .25$ & $<0.001^{*}$ & $<0.001^{*}$ & $<0.001^{*}$ \\
\hline Placental weight/g & $567.98 \pm 54.63$ & $486.47 \pm 38.88$ & $422.37 \pm 45.83$ & $<0.001^{*}$ & $<0.001^{*}$ & $<0.001^{*}$ \\
\hline $\begin{array}{l}\text { Gestational age at } \\
\text { delivery } / w\end{array}$ & $39.54 \pm .56$ & $37.65 \pm .99$ & $33.66 \pm .62$ & $<0.001^{*}$ & $<0.001^{*}$ & $<0.001^{*}$ \\
\hline $\begin{array}{l}\text { Mean pulstile } \\
\text { index }\end{array}$ & $2.73 \pm .08$ & $2.60 \pm .40$ & $1.25 \pm .42$ & $>0.05 \mathrm{NS}$ & $<0.001^{*}$ & $<0.001^{*}$ \\
\hline
\end{tabular}

Values are mean \pm S.D

$\mathbf{P 1}=$ between normotensive and mild preeclampsia groups.

$\boldsymbol{P 2}=$ between normotensive and severe preeclampsia groups.

$\mathbf{P 3}=$ between mild preeclampsia and severe preeclampsia group s.

$N S=$ Non significant.

*= Significant.

Table (2): Mean values \pm standard deviation of measured parameters estimating the extent of preeclampsia in all studied groups.

\begin{tabular}{|c|c|c|c|c|}
\hline Parameter/Group & Normotensive & Mild preclampsia & severe preclampsia & Pvalue \\
\hline$P L G F(p g / m l)$ & $407.55 \pm 149.82$ & $260.73 \pm 112.37$ & $174.97 \pm 116.48$ & $\begin{array}{l}\mathrm{P} 1>0.05(\mathrm{NS}) \\
\mathrm{P} 2<0.001^{*} \\
\mathrm{P} 3<0.001^{*}\end{array}$ \\
\hline sVEGFR1 $(\mathrm{pg} / \mathrm{ml})$ & $1101.70 \pm 157.86$ & $4707.05 \pm 2134.32$ & $5184.21 \pm 1652.60$ & $\begin{array}{l}\mathrm{P} 1<0.001^{*} \\
\mathrm{P} 2<0.001^{*} \\
\mathrm{P} 3>0.05 \text { (NS) }\end{array}$ \\
\hline $\begin{array}{l}\text { NO products } \\
\text { (umol/L) }\end{array}$ & $117.17 \pm 28.42$ & $43.25 \pm 23.84$ & $38.70 \pm 12.53$ & $\begin{array}{l}\mathrm{P} 1<0.001 * \\
\mathrm{P} 2<0.001 * \\
\mathrm{P} 3>0.05(\mathrm{NS})\end{array}$ \\
\hline
\end{tabular}

$\boldsymbol{P 1}=$ between normotensive and mild preeclamp sia groups.

$\boldsymbol{P 2}=$ between normotensive and severe preeclampsia groups.

$\boldsymbol{P 3}=$ between mild preeclampsia and severe preeclampsia group $\mathrm{s}$

$\boldsymbol{N S}=$ Non significant.

*= Significant. 
Table (3): Receiver operating characteristic curves of the maternal plasma concentration of PIGF, s VEGFR-1 and NO products for the identification of patients destined to develop preeclampsia

\begin{tabular}{|l|l|l|l|l|l|}
\hline $\begin{array}{l}\text { Test Result } \\
\text { Variable(s) }\end{array}$ & $\begin{array}{l}\text { Cut off } \\
\text { value }\end{array}$ & $\begin{array}{l}\text { Sensitivity } \\
\text { (\%) }\end{array}$ & $\begin{array}{l}\text { Specificity } \\
\text { (\%) }\end{array}$ & $\begin{array}{l}\text { Area under } \\
\text { the curve }\end{array}$ & p-value \\
\hline PLGF $(\mathbf{p g} / \mathbf{m l})$ & $\leq 286.32$ & 80.00 & 80.70 & .854 & $<0.001$ \\
\hline sVEGFR1 $(\mathbf{p g} / \mathbf{m l})$ & $\geq 2005.00$ & 98.20 & 100.00 & .982 & $<0.001$ \\
\hline NO products $($ umol/L) & $\leq 50.90$ & 90.90 & 100.00 & .985 & $<0.001$ \\
\hline
\end{tabular}

Table (4): Receiver operating characteristic curves of the maternal plasma concentration of PlGF , s VEGFR-1 and NO products for the identification of patients destined to develop severe preeclampsia.

\begin{tabular}{|l|l|l|l|l|l|}
\hline Test Result Variable(s) & $\begin{array}{l}\text { Cutoff } \\
\text { value }\end{array}$ & $\begin{array}{l}\text { Sensitivity } \\
\text { (\%) }\end{array}$ & $\begin{array}{l}\text { Specificity } \\
\text { (\%) }\end{array}$ & $\begin{array}{l}\text { Area under } \\
\text { the curve }\end{array}$ & p-value \\
\hline PLGF $(\mathbf{p g} / \mathbf{m l})$ & $\leq 234.56$ & 81.60 & 85.10 & .867 & $<0.001$ \\
\hline sVEGFR1 $(\mathbf{p g} / \mathbf{m l})$ & $\geq 2900.00$ & 100.00 & 81.10 & .901 & $<0.001$ \\
\hline NO products(umol/L) & $\leq 54.00$ & 81.60 & 79.70 & .878 & $<0.001$ \\
\hline
\end{tabular}

Table (5): Correlations between the estimated maternal plasma PlGF , sVEGFR-1 and NO products versus other variables among preeclampatic patients $(\mathrm{n}=55)$.

\begin{tabular}{|c|c|c|c|}
\hline & $P L G F(p g / m l)$ & $\begin{array}{l}\text { SVEGFR1 } \\
(\mathrm{pg} / \mathrm{ml})\end{array}$ & $\begin{array}{l}\text { NO products } \\
\text { (umol/L) }\end{array}$ \\
\hline$B M I \mathrm{Kg} / \mathrm{m} 2$ & $\begin{array}{l}\boldsymbol{r}=-0.24 \\
\boldsymbol{P}=0.009\end{array}$ & $\begin{array}{l}\boldsymbol{r}=0.30 \\
\boldsymbol{P}=0.001\end{array}$ & $\begin{array}{l}\boldsymbol{r}=-0.44 \\
\boldsymbol{P}<0.001\end{array}$ \\
\hline$\overline{S B P}$ & $\begin{array}{l}\boldsymbol{r}=-0.54 \\
\boldsymbol{P}=<0.001\end{array}$ & $\begin{array}{l}\boldsymbol{r}=0.79 \\
\boldsymbol{P}<0.001\end{array}$ & $\begin{array}{l}\boldsymbol{r}=-0.76 \\
\boldsymbol{P}<0.001\end{array}$ \\
\hline$\overline{D B P}$ & $\begin{array}{l}\boldsymbol{r}=-0.56 \\
\boldsymbol{P}=<0.001\end{array}$ & $\begin{array}{l}\boldsymbol{r}=0.79 \\
\boldsymbol{P}<0.001\end{array}$ & $\begin{array}{l}\boldsymbol{r}=-0.72 \\
\boldsymbol{P}<0.001\end{array}$ \\
\hline Birth weight/kg & $\begin{array}{l}\boldsymbol{r}=0.54 \\
\boldsymbol{P}<0.001\end{array}$ & $\begin{array}{l}\boldsymbol{r}=-0.39 \\
\boldsymbol{P}<0.001\end{array}$ & $\begin{array}{l}\boldsymbol{r}=0.70 \\
\boldsymbol{P}<0.001\end{array}$ \\
\hline Placental weight/g & $\begin{array}{l}\boldsymbol{r}=0.45 \\
\boldsymbol{P}<0.001\end{array}$ & $\begin{array}{l}\boldsymbol{r}=-0.27 \\
\boldsymbol{P}=0.003\end{array}$ & $\begin{array}{l}\boldsymbol{r}=0.68 \\
\boldsymbol{P}<0.001\end{array}$ \\
\hline $\begin{array}{l}\text { Gestational age at } \\
\text { delivery/w }\end{array}$ & $\begin{array}{l}\boldsymbol{r}=0.58 \\
\boldsymbol{P}<0.001\end{array}$ & $\begin{array}{l}\boldsymbol{r}=-0.36 \\
\boldsymbol{P}<0.001\end{array}$ & $\begin{array}{l}\boldsymbol{r}=0.75 \\
\boldsymbol{P}<0.001\end{array}$ \\
\hline $\begin{array}{l}\text { Mean pulstile } \\
\text { index }\end{array}$ & $\begin{array}{l}\boldsymbol{r}=0.50 \\
\boldsymbol{P}<0.001\end{array}$ & $\begin{array}{l}\boldsymbol{r}=-0.41 \\
\boldsymbol{P}<0.001\end{array}$ & $\begin{array}{l}\boldsymbol{r}=\mathbf{0 . 6 2} \\
\boldsymbol{P}<0.001\end{array}$ \\
\hline$P L G F(p g / m l)$ & & $\begin{array}{l}\boldsymbol{r}=-0.47 \\
\boldsymbol{P}<0.001\end{array}$ & $\begin{array}{l}\boldsymbol{r}=0.47 \\
\boldsymbol{P}<0.001\end{array}$ \\
\hline SVEGFR1 (pg/ml) & $\begin{array}{l}\boldsymbol{r}=-0.47 \\
\boldsymbol{P}<0.001\end{array}$ & & $\begin{array}{l}\boldsymbol{r}=-0.73 \\
\boldsymbol{P}<0.001\end{array}$ \\
\hline $\begin{array}{l}\text { NO products } \\
\text { (umol/L) }\end{array}$ & $\begin{array}{l}\boldsymbol{r}=0.47 \\
\boldsymbol{P}<0.001\end{array}$ & $\begin{array}{l}\boldsymbol{r}=-0.73 \\
\boldsymbol{P}<0.001\end{array}$ & \\
\hline
\end{tabular}




\section{$\underline{P I G F(p g / m l)}$}

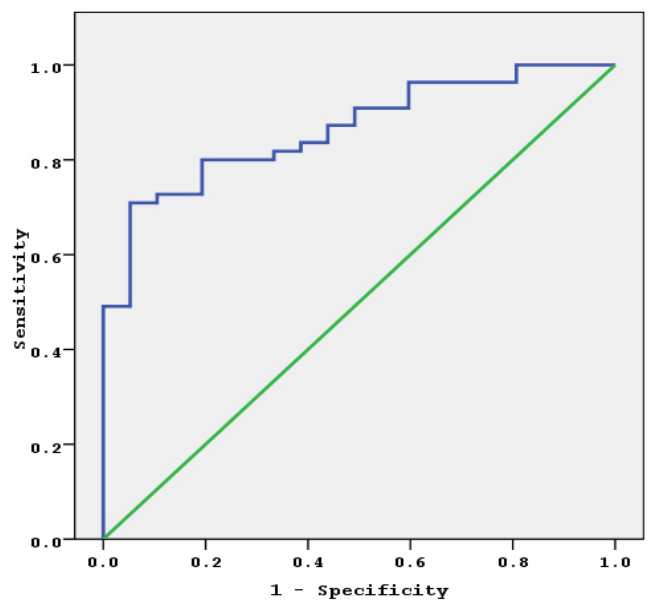

\section{NO products(umol/L)}

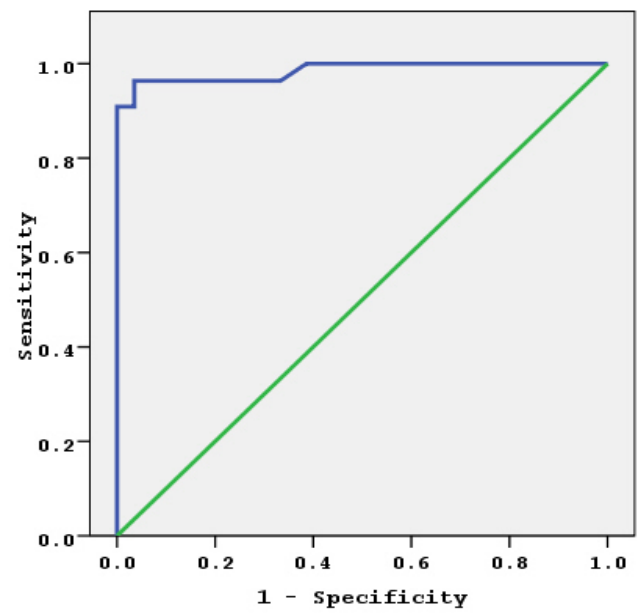

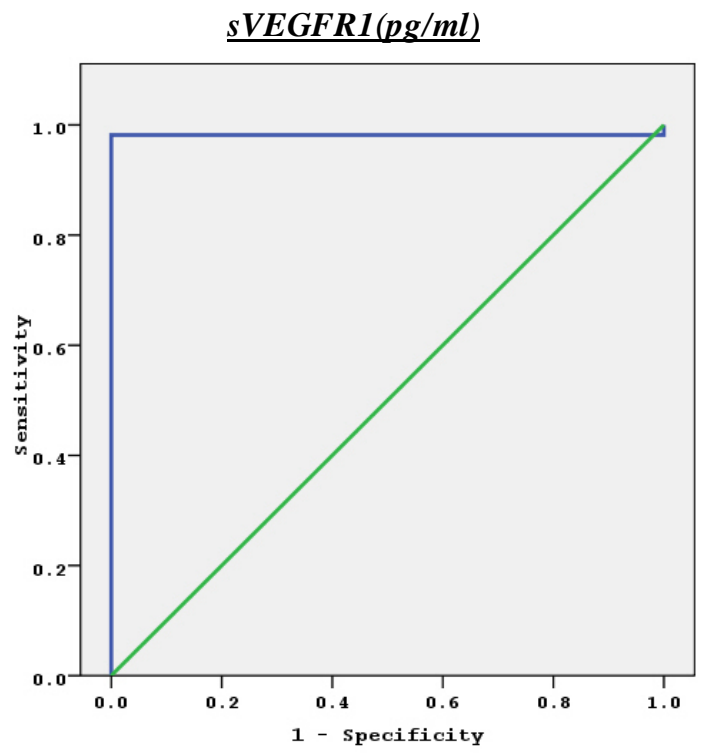

Fig. (1): Receiver operating characteristic curves of the maternal plasma concentration of PlGF, sVEGFR-1 and NO products for the identification of patients destined to develop preeclampsia 


\section{$\underline{\text { SVEGFR1 }(\mathrm{pg} / \mathrm{ml})}$}

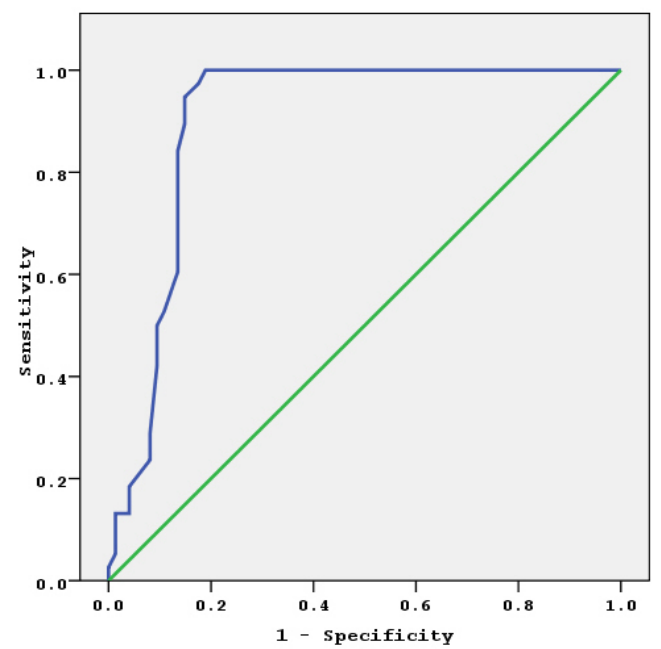

\section{$\underline{P L G F(p g / m l)}$}

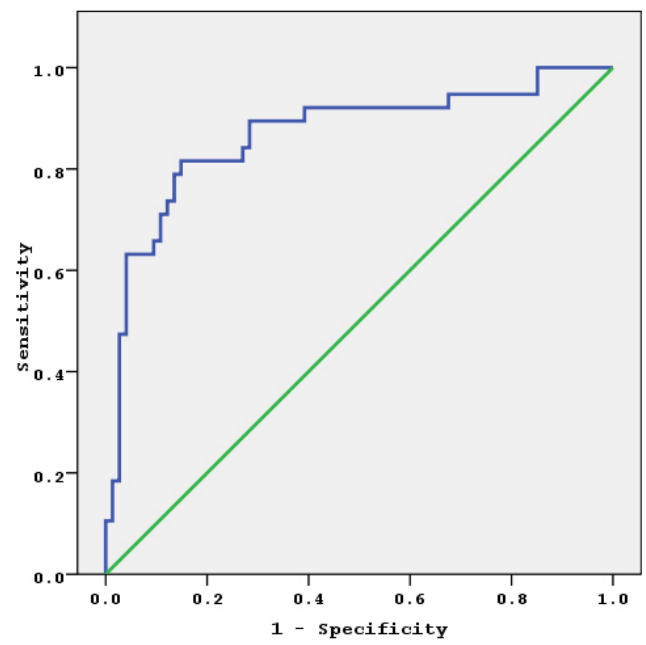

\section{NO products(umol/L)}

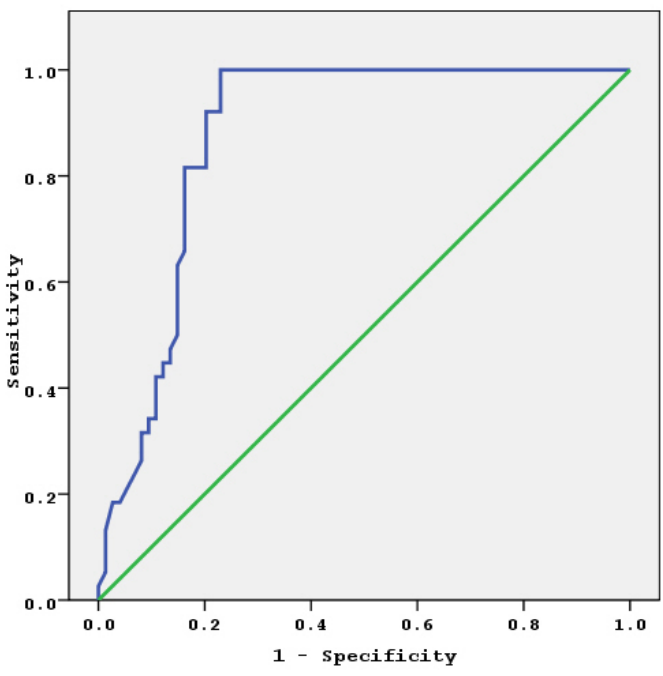

Fig. (2): Receiver operating characteristic curves of the maternal plasma concentration of PlGF , sVEGFR-1 and NO products for the identification of patients destined to develop severe preeclampsia 


\section{DISCUSSION}

Considerable clinical evidence has accumulated that preeclampsia is strongly linked to an imbalance between proangiogenic (VEGF and PlGF) and antiangiogenic (sFlt-1) factors in the maternal circulation (9). Recently, studies have reported that increased sFlt-1 may have a predictive value in diagnosing preeclampsia since concentrations seem to increase before manifestation of overt symptoms as hypertension and proteinuria $^{(9)}$.

The present study showed significant increase in mean maternal sVEGFR1 levels in subjects who developed mild and severe preeclampsia, as compared with those who did not develop preeclampsia, in contrast to the mean serum levels of maternal PLGF which were significantly lower which is concomitant with the results of the study done by Moore Simas et $\boldsymbol{a l}^{(\mathbf{2 9})}$, who found that mean sFlt1 levels were significantly higher in subjects who developed preeclampsia prior to 34 weeks, compared with those without preeclampsia, and that the mean PIGF levels tended to be lower for subjects who developed preeclampsia as compared with those without preeclampsia. They studied sFlt1 to PlGF ratio as an index of antiangiogenic activity that reflects changes in the balance between sFlt1 and PlGF, and they suggested that it has been shown to be more strongly associated with preeclampsia than either measure alone in healthy women. From their study they concluded that in high-risk women, serum sFlt1 and the sFlt1: PIGF ratio are altered prior to preeclampsia onset and may be predictive of preeclampsia.

In the current study, Receiver operating characteristic curves were constructed to describe the relationship between sensitivity and the false-positive rate (1-specificity) of plasma PlGF, sVEGFR-1 and NO products in the identification of patients destined to develop preeclampsia. sVEGFR1 (pg/ml) and NO products (umol/L) were found to be the best predictors for preeclampsia with high sensitivity and specificity followed by PLGF (pg/ml).While in severe preeclampsia s VEGFR1 (pg/ml) was the best followed by NO products (umol/L) then PLGF (pg/ml). Logistic regression analysis indicated that a maternal plasma concentration of sVEGFR1 $\geq 2005 \mathrm{pg} / \mathrm{mL}, \quad$ NO products $\leq 50.9$ umol/L and PLGF $\leq 286.3 \mathrm{pg} / \mathrm{ml}$ were independent variables for the occurrence of preeclampsia. The results of Espinoza et $\boldsymbol{a l}^{(30)}$ are in agreement with these results in their study of identification of patients at risk for early onset and/or severe preeclampsia with the use of uterine artery Doppler velocimetry and placental growth factor, they stated that a maternal plasma concentration of $\mathrm{PlGF} \leq 280$ $\mathrm{pg} / \mathrm{mL}$ was an independent explanatory variable for the occurrence of preeclampsia, early onset preeclampsia, severe preeclampsia, In contrast, maternal plasma sVEGFR-1 concentration was of limited value in the prediction of early onset and severe preeclampsia.

Also the present results are consistent with previous reports by Stepan et al ${ }^{(23)}$ indicating that a low 
maternal plasma concentration of PlGF in the first or second trimester of pregnancy and abnormal UADV results between 23 and 25 weeks of gestation are risk factors for the development of preeclampsia. Hawever, the results of $\mathbf{M u l l e r}$ et $\boldsymbol{a l}^{(31)}$ differ from those results, indicating a lack of association between abnormal UADV and low PIGF. Differences in sample size, gestational age at ultrasound, and study outcomes may account for these discrepancies.

Muy-Rivera et $\boldsymbol{a l}^{(32)}$ examined the relationship of maternal plasma VEGF, sVEGF-R1 and PlGF levels to the risk of preeclampsia among Zimbabwean women and noted a strong positive association between preeclampsia risk and sVEGF-R1 concentrations, while there was no clear evidence of a linear relation in risk of preeclampsia with PlGF concentrations (Maternal plasma PIGF concentrations were similar in both cases and controls).

Our results in high concentrations of sVEGF-R1 in plasma of preeclamptic women are consistent with those reported by Chaiworapongsa et al $^{(33)}$ and Levine et $\boldsymbol{a l}^{\mathbf{( 1 5 )}}$. Moreover, it has also been shown that placentas from preeclamptic women produce higher concentrations of sVEGF-R1 in vitro as compared to controls $\left.{ }^{(34,} 35\right)$. Interestingly, the increase of sVEGF$\mathrm{R} 1$ corresponds to a decrease of free VEGF and PlGF in the serum of patients with preeclampsia resulting in endothelial dysfunction (15). sVEGF$\mathrm{R} 1$ is a major contributor to the pathogenesis of preeclampsia. It has been shown in animal models that the administration of sVEGF-R1 induces hypertension, proteinuria and glomerular endotheliosis in pregnant rats ${ }^{(5)}$.

Many researchers have spent years trying to find the cause of preeclampsia but the mechanism remains elusive. It is possible that diminished maternal serum levels of PlGF and increased levels of s-Flt1 may contribute to increased vascular permeability. However, it is just as likely these serum proteins are just markers for the disease and have no role in the mechanism.

Christopher et $\mathbf{a l}^{(36)}$ in their study evaluating placenta growth factor and soluble Fms-like tyrosine kinase 1 receptor levels in mild and severe preeclampsia, stated that serum PlGF is lower in patients with severe preeclampsia compared with mild preeclampsia, while that s-Flt1 levels are higher in patients with severe preeclampsia though not statistically significant compared with mild preeclampsia.

To determine if PlGF serum levels decrease and s-Flt1 increase as the disease progresses, the more ideal study design would be to follow patients longitudinally. PIGF serum concentrations peak at 26 to 30 weeks and then decline as term approaches $^{(37)}$. S-Flt1 has a stable concentration until 33 to 36 weeks and then increases about $145 \mathrm{pg} / \mathrm{mL}$ per week $^{(\mathbf{1 5 )}}$.

The current study showed significantly decreased maternal NO product serum levels in mild and severe cases and suggested that it is a predictor for the occurrence of mild and severe preeclampsia which is consistent with the results of $\boldsymbol{E} \boldsymbol{b r u}$ et $\boldsymbol{a l}^{(\mathbf{3 8})}$ in their study of the changes of 
plasma malondialdehyde, nitric Oxide, and adrenomedullin(ADM) Levels in patients with preeclampsia, they concluded that the plasma levels of ADM and NO are decreased while MDA levels are increased in subjects with preeclampsia which might contribute to the pathophysiology of preeclampsia through the lack of a paracrine vasodilatory effect on uteroplacental blood flow. Also, previously Seligman et $\boldsymbol{a l}^{(39)}$ stated that circulating levels of nitrite are decreased in patients with preeclampsia. These data support the concept that diminished nitric oxide synthesis contributes to the pathophysiologic changes seen in preeclampsia. Tranquilli et $\boldsymbol{a l}^{(\mathbf{1 2})}$ assessed whether amniotic fluid concentrations of nitric oxide (NO) and vascular endothelial growth factor (VEGF) in early pregnancy correlate to subsequent preeclampsia and found that they were significantly lower than healthy controls and thus concluded that, low concentrations of VEGF and $\mathrm{NO}$ in the second trimester may represent an impaired stimulus to vascular formation and endothelial regulation that induces placental disease and preeclampsia. All the above findings are consistent with the finding of the current study in that low NO concentrations in the maternal blood is implicated in pathogenesis of preeclampsia and could be considered as a potential predictor marker for the disease, and it is the first work that studied the role of $\mathrm{NO}$ in the prediction of preeclampsia.

\section{Conclusion}

The results of the current study suggested that the identification of high concentrations of sFlt-1 combined with low concentrations of PIGF and NO products, could be used to predict the development of preeclampsia. This may be beneficial in identification of patients at high risk for the early and/or a more severe form of preeclampsia, in whom prophylactic interventions are more likely to reduce the morbidity and mortality rates associated with that obstetric syndrome.

\section{REFERENCES}

\section{Sibai B, Dekker G, Kupferminc} M. (2005): Pre-eclampsia. Lancet 365: 785-799.

2. Irgens $\mathbf{H U}$, Reisaeter $L$, Irgens LM, Lie RT. (2001): Long-term mortality of mothers and fathers after pre-eclampsia: population based cohort study. BMJ 323: 1213-1217..

3. Fisher SJ, Roberts JM. (1999): Defects in placentation and placental perfusion. In: Chelsey's Hypertensive Disorders in Pregnancy, edited by Lindheimer MD, Roberts JM, and Cunningham FG. Stanford, CT: Appleton \& Lange, , p. 377-394.

4. Conrad KP, Benyo DF. (1997): Placental cytokines and the pathogenesis of preeclampsia. Am J Reprod Immunol 37: 240-249.

5. Maynard SE, Min JY, Merchan J, Lim KH, Li J, Mondal S, Libermann TA, Morgan JP, Sellke FW, Stillman IE, Epstein FH, Sukhatme VP, Karumanchi SA. (2003): Excess placental soluble fms-like tyrosine kinase 1 (sFlt1) may contribute to endothelial dysfunction, hypertension, and 
proteinuria in preeclampsia. $J$

Clin Invest 111: 649-658.

6. Rinehart BK, Terrone DA, Lagoo-Deenadayalan S, Barber WH, Hale EA, Martin JN Jr, Bennett WA. (1999): Expression of the placental cytokines tumor necrosis factor alpha, interleukin 1beta, and interleukin 10 is increased in preeclampsia. Am $J$ Obstet Gynecol 181: 915-920.

7. Bdolah Y, Sukhatme VP, Karumanchi SA. (2004): Angiogenic imbalance in the pathophysiology of preeclampsia: newer insights. Semin Nephrol 24: 548-556.

8. Karumanchi SA, Bdolah Y. (2004): Hypoxia and sFlt-1 in preeclampsia: the "chicken-andegg" question. Endocrinology 145: 4835-4837.

9. Lam C, Lim KH, Karumanchi SA: (2005): Circulating angiogenic factors in the pathogenesis and prediction of preeclampsia. Hypertension 46: 1077-1085.

10. Wolf M, Shah A, Lam C, Martinez A, Smirnakis KV, Epstein FH, Taylor RN, Ecker JL, Karumanchi SA, Thadhani R. (2005): Circulating levels of the antiangiogenic marker sFLT-1 are increased in first versus second pregnancies. Am J Obstet Gynecol 193: 16-22.

11. Rana S, Karumanchi SA, Levine RJ, Venkatesha $S$, Rauh-Hain JA, Tamez H, Thadhani R. (2007): Sequential changes in antiangiogenic factors in early pregnancy and risk of developing preeclampsia. Hypertension 50: 137-142.
12. Tranquilli AL, Bezzeccheri V, Giannubilo SR, Scagnoli C, Mazzanti L, Garzetti GG.( 2004) : Amniotic vascular endothelial growth factor (VEGF) and nitric oxide (NO) in women with subsequent preeclampsia. Eur J Obstet Gynecol Reprod Biol 113: 17-20.

13. Abid M, Schoots I, Spokes K, Wu S, Mawhinney C, Aird W. (2004): Vascular endothelial growth factor-mediated induction of manganese superoxide dismutase occurs through redoxdependent regulation of forkhead and $\leqslant \mathrm{B} / \mathrm{NF}-\mathrm{k} \mathrm{B} . \quad J$ Biol Chem 279: 44030-44038..

14. Clark DE, Smith SK, He Y, Day KA, Licence DR, Corps AN, Lammoglia R, Charnock-Jones DS. (1998): A vascular endothelial growth factor antagonist is produced by the human placenta and released into the maternal circulation. Biol Reprod 59: 1540-1548.

15. Levine RJ, Maynard SE, Qian C, Lim KH, England LJ, Yu KF, Schisterman EF, Thadhani R, Sachs BP, Epstein FH, Sibai BM, Sukhatme VP, Karumanchi SA. (2004): Circulating angiogenic factors and the risk of preeclampsia. $N$ Engl J Med 350: 672-683.

16. Kendall RL, Wang G, Thomas KA. (1996): Identification of a natural soluble form of the vascular endothelial growth factor receptor, FLT-1, and its heterodimerization with KDR. Biochem Biophys Res Commun 226: 324-328. 
17. Lu F, Longo M, Tamayo E, Maner W, Al-Hendy A, Anderson GD, Hankins GD, Saade GR. (2007): The effect of over-expression of sFlt-1 on blood pressure and the occurrence of other manifestations of preeclampsia in unrestrained conscious pregnant mice. Am $J$ Obstet Gynecol 196: e1-e7.

18. Levine RJ, Lam C, Qian C, Yu KF, Maynard SE, Sachs BP, Sibai BM, Epstein FH, Romero R, Thadhani R, Karumanchi SA. (2006): Soluble endoglin and other circulating antiangiogenic factors in preeclampsia. $N$ Engl $J$ Med 355: 992-1005.

19. Sladek SM, Magness RR, Conrad KP. (1997): Nitric oxide and pregnancy. Am $J$ Physiol Regul Integr Comp Physiol 272: R441-R463.

20. Conrad KP. (1990): Animal models of pre-eclampsia: do they exist? Fetal Medicine Review 2: 67-88.

21. Kassab S, Miller MT, Hester R, Novak J, Granger JP. (1998): Systemic hemodynamics and regional blood flow during chronic nitric oxide synthesis inhibition in pregnant rats. Hypertension 31: 315-320.

22. Papageorghiou AT, Yu CK, Cicero S, Bower S, Nicolaides KH. (2002): Second-trimester uterine artery Doppler screening in unselected populations: a review. J Matern Fetal Neonatal Med 12:78-88.

23. Stepan $H$, Faber $R$, Wessel $N$, Wallukat G, Schultheiss HP, Walther T. (2006): Relation between circulating angiotensin II type 1 receptor agonistic autoantibodies and soluble fmslike tyrosine kinase 1 in the pathogenesis of preeclampsia. J Clin Endocrinol Metab 91:24247.

24. American College of Obstetricians and Gynecologist Practice Bulletin. (2002): Diagnosis and management of preeclampsia and eclampsia. Obstet Gynecol 99:159-67.

25. Bower S, Schuchter K, Campbell S. (1993): Doppler ultrasound screening as part of routine antenatal scanning: prediction of pre-eclampsia and intrauterine growth retardation. BJOG 100:989-94.

26. Maynard SE, Min JY, Merchan J, et al. (2003): Excess placental soluble fms-like tyrosine kinase 1 (sFlt1) may contribute to endothelial dysfunction, hypertension, and proteinuria in preeclampsia. $\mathrm{J}$ Clin Invest 111:649-658

27. A. Caretti, P. Bianciardi, $\mathbf{R}$. Ronchi, M. Fantacci, M. Guazzi, and M. Samaja (2008): Phosphodiesterase-5 Inhibition Abolishes Neuron Apoptosis Induced by Chronic Hypoxia Independently of HypoxiaInducible Factor-1\{alpha\} Signaling. Exp Biol Med, October 1; 233(10): 1222 - 1230

28. Solitro $M$, Moore Simas $T$, Frost S, Rajan A, Crawford S, Maynard SE. (2006): Circulating soluble fms-like tyrosine kinase-1 (sFlt1) is increased in multiple gestation vs. singleton pregnancies. Presented at the $39^{\text {th }}$ Annual Meeting of the 
American Society of Nephrology, San Diego, CA.

29. Moore Simas TA, Crawford SL, Solitro MJ, et al. (2007): Angiogenic factors for the prediction of preeclampsia in high-risk women. Am J Obstet Gynecol 197:244:e1-e8.

30. Espinoza J, Romero $R$, Nien JK, et al. (2007): Identification of patients at risk for early onset and/or severe preeclampsia with the use of uterine artery Doppler velocimetry and placental growth factor. Am J Obstet Gynecol 196:326:e1-e13.

31. Muller PR, James AH, Murtha PP, Yonish B, Jamison MG, Dekker G. (2006): Circulating angiogenic factors and abnormal uterine artery Doppler velocimetry in the second trimester. Hypertens Pregnancy 25:183-92.

32. Muy- Rivera M, Vadachkoria S, Woelk GB, Qiu C, Mahomed K, Williams MA.(2005): Maternal Plasma VEGF, sVEGF$\mathrm{R} 1$, and PlGF concentrations in preeclamptic and normotensive pregnant Zimbabwean Women. Physiol; Res. 54: 611-622.

33. Chaiworapongsa $T$, Romero $R$, Espinoza J, Bujold E, Mee Kim Y, Goncalvse LF, Gomez R, Edwin S. (2004): Evidence supporting a role for blockade of the vascular endothelial growth factor system in the pathophysiology of preeclampsia. Am J Obstet Gynecol 190: 15411547.

34. Zhou Y, McMaster M, Woo K, Janatpour M, Perry J, Karpanen T, Alitalo K, Damsky
C, Fisher SJ. (2002): Vascular endothelial growth factor ligands and receptors that regulate human cytotrophoblast survival are dysregulated in severe preeclampsia and hemolysis, elevated liver enzymes, and low platelets syndrome. Am J Pathol 160: 1405-1423.

35. Helske S, Vuorela P, Carpen $O$, Hornig C, Weich $H$, Halmesmaki E. (2001): Expression of vascular endothelial growth factor receptors 1,2 and 3 in placentas from normal and complicated pregnancies. Mol Hum Reprod 7: 205-210.

36. Christopher J. Robinson, Donna D. Johnson, Eugene Y. Chang, D. Michael Armstrong, Wei Wang. (2006): Evaluation of placenta growth factor and soluble Fms-like tyrosine kinase 1 receptor levels in mild and severe preeclampsia American Journal of Obstetrics and Gynecology; 195, 255-9.

37. Tidwell SC, Ho HN, Chiu WH, Torry RJ, Torry DS. (2001): Low maternal serum levels of placenta growth factor as an antecedent of clinical preeclampsia. Am J Obstet Gynecol 184:1267-72.

38. Ebru Dikensoy, Ozcan Balat, Sadrettin Pence, Ayse Balat, Mustafa Cekmen Muhuttin Yurekli. (2009): The Changes of Plasma Malondialdehyde, Nitric Oxide, and Adrenomedullin Levels in Patients with Preeclampsia. Hyprtension in Pregnancy. 28(4): 383-389. 
39. Seligman SP;

Clancy RM;

Abrams on SB. (1994): The role of nitric oxide in the pathogenesis

of preeclampsia. Am J Obstet

Gynecol. 171(4):944-8

\title{
دراسة دور عامل نمو بطانة الاوعية الدموية و أكسيد النيتريك

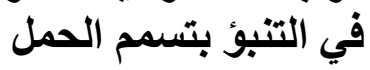

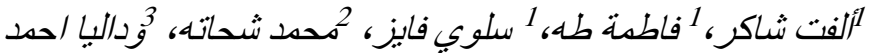

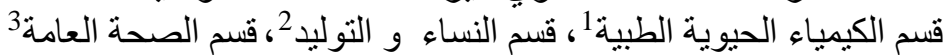 \\ كلية الطب جامعة القاهرة
}

خلفية يعد تسمم الحمل حالة مرضية مضادة لتكون الأوعية الدموية و يمكن اكتثافها عن طريق قياس تركيز مستقبلات عامل نمو بطانة الاو عية الدموية الذائب -

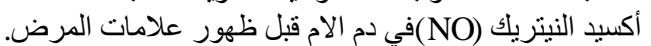

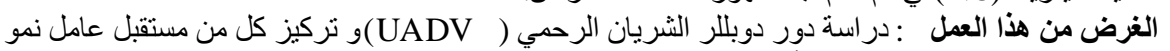

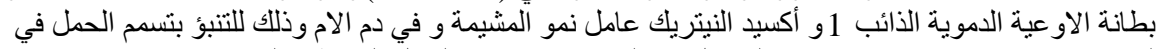

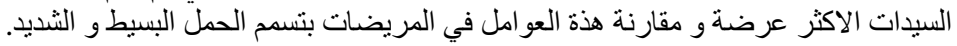

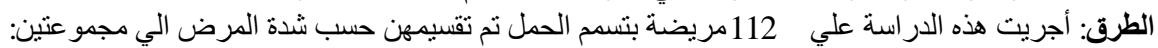

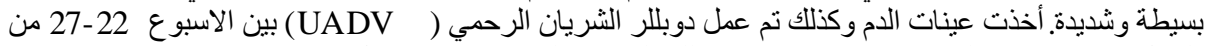

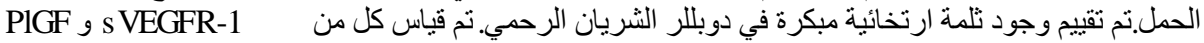

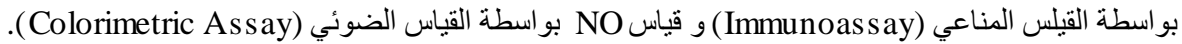
النتائج : في المريضات اللائي اظهرن نتائج غير طبيعية بواسطة

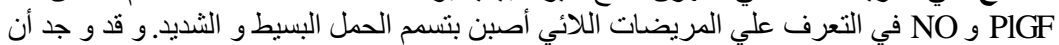

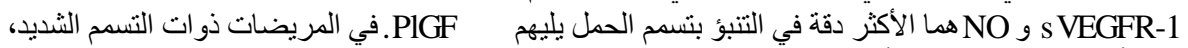

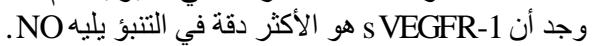

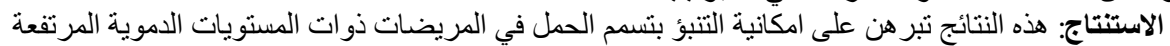

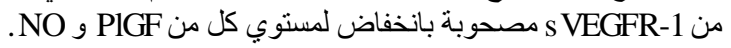

